\title{
POR UMA EDUCAÇÃO AMBIENTAL CRÍTICA NA SOCIEDADE ATUAL
}

\author{
Mauro GUIMARÃES \\ Universidade Federal Rural do Rio de JaneiroUFRRJ ${ }^{1}$ \\ guimamauro@hotmail.com
}

Resumo: O objetivo deste breve ensaio é trazer alguns questionamentos iniciais que nos levem a refletir sobre alguns limites e potencialidades da Educação Ambiental e a transformação da sociedade atual.

Palavras-chaves: Educação Ambiental. Concepção Crítica. Transformação Social.

Abstract: This purpose of this brief essay is to bring some initial questioning that lead to reflect on some limits and potential of Environmental Education and the transformation of society.

Keywords: Environmental Education. Critical Approach. Social Transformation.

\section{Introdução}

A atualidade da grave crise socioambiental, que "se produz neste período histórico, onde o poder das forças desencadeadas num lugar ultrapassa a capacidade local de controlá-las, nas condições atuais de mundialidade e de suas repercussões nacionais.” (Santos, 1997), gera problemas socioambientais locais e globais, que demandam uma reflexão entre o micro e o macro e o enfrentamento de toda a sociedade. Justifica-se assim refletir sobre Educação - Meio Ambiente - Sociedade em uma perspectiva relacional.

\section{Educação Ambiental: uma reflexão necessária}

Internacionalmente, a Educação Ambiental alcança maior projeção com a Conferência da ONU sobre o Ambiente Humano - Estocolmo (72); aproximadamente a 40 anos atrás, um tempo histórico muito breve.

\footnotetext{
${ }^{1}$ Professor do Programa de Mestrado em Educação (PPGEduc) Coordenador do Grupo de Estudos e Pesquisas em Educação Ambiental, Diversidade e Sustentabilidade (GEPEADS).
} 
Neste período reconheceu-se a Educação Ambiental como o elemento crítico para o combate à crise ambiental no mundo.

No Brasil, o movimento ambientalista ganha peso a partir do início dos anos 80 , com o processo de redemocratização da sociedade brasileira e a chegada de exilados políticos que se envolveram com o movimento ambientalista no exterior. A Educação Ambiental (EA) neste momento inicial se deu informalmente nas ações militantes, que buscavam difundir os ideais ambientalistas. Este movimento ganha força com os preparativos para a Rio 92, quando acredito que a EA chega de forma institucional ao sistema de ensino formal. Neste período temos as primeiras iniciativas mais consistentes junto às secretarias de educação e no próprio MEC e, mais tarde ainda, começa a se inserir nas Universidades. Portanto, a meu ver, o processo de formação dos primeiros educadores ambientais brasileiros se deu muito na militância do movimento e foi "contaminando" pouco a pouco os professores dentro das escolas. Vejo que hoje a EA já vem se institucionalizando em todos os níveis de ensino, mas que em conjunto a isso há também uma militância dos professores que buscam, independente das secretarias, Ministérios e oficialidades, inseri-la em suas práticas pedagógicas. Acho que é nestes movimentos que se entrecruzam, inclusive também que se conflituam, que vem se dando o contexto de formação dos atores que desejam uma sociedade socioambientalmente sustentável.

Realiza-se em 1992 a Conferência das Nações Unidas sobre Meio Ambiente e Desenvolvimento no Rio de Janeiro, em que, entre os vários documentos produzidos, destaca-se a Agenda 21 que consagra o Capítulo 38, "a promoção da educação, da consciência política e do treinamento", e apresenta um plano de ação para o desenvolvimento sustentável. Também durante a Rio 92, diversas Organizações da Sociedade Civil elaboraram o Tratado de Educação Ambiental para Sociedades Sustentáveis e responsabilidade Global, de caráter não oficial, o qual reconhece a educação como um processo dinâmico em permanente construção cidadã. Deve, portanto, propiciar a reflexão, o debate e a autotransformação das pessoas e da realidade social. Reconhece que a Educação Ambiental para a sustentabilidade equitativa é um processo de aprendizagem permanente baseado no respeito a todas as formas de vida. 
Em dezembro de 1997 ocorreu a Conferência de Thessaloniki (Grécia), Conferência Meio Ambiente e Sociedade: Educação e Consciência Pública para a sustentabilidade, na qual mais uma vez discutiu-se o desenvolvimento e os rumos da Educação Ambiental em todo o mundo. Nesta oportunidade reafirmou-se o que foi apresentado nas duas grandes reuniões intergovernamentais anteriores, Tbilisi (1977) e Moscou (1987), que a Educação Ambiental deve ser implementada de acordo com as orientações de Tbilisi e de sua evolução a partir das questões globais tratadas na Agenda 21 e nas grandes Conferências da ONU, que também abordaram a educação para sustentabilidade. Em 2007, na Índia, mais uma vez ocorre a Conferência decenal de Educação Ambiental, mas sem trazer ainda nenhuma grande novidade, para além do que já vinha se configurando.

No Brasil a Educação Ambiental vem se concretizando principalmente a partir da década de $80 . \mathrm{Na}$ Constituição federal de 1988, no Capítulo VI sobre o meio ambiente, é instituído como competência do poder público a necessidade de "promover a Educação Ambiental em todos os níveis de ensino" (art. 225, parág. 1. Inciso VI). A abertura dada à Educação Ambiental pela Constituição federal vem favorecendo a sua institucionalização perante a sociedade brasileira, tanto que a atual Lei de Diretrizes e Bases da Educação Nacional determina que esta perspectiva de Educação seja considerada uma diretriz para os conteúdos curriculares da Educação Fundamental. Desta forma o Ministério da Educação e desportos (MEC) elaborou os Parâmetros Curriculares Nacionais (PCN) no qual o meio ambiente (Educação Ambiental) é apresentado como tema transversal para todo o currículo, tratado de forma articulada entre as diversas áreas do conhecimento, de forma a impregnar toda a prática educativa e, ao mesmo tempo, criando uma visão global e abrangente da questão ambiental.

Em 1997, o Ministério do Meio Ambiente, o Ministério da Educação, o Ministério da Ciência e da Tecnologia e o Ministério da Cultura apresentaram, conjuntamente, o Programa Nacional de Educação Ambiental (PRONEA), revisado por consulta pública em 2005, que busca, por meio de seus princípios e linhas de ações propostos, intensificar a implantação da Educação Ambiental na sociedade nacional. 
Em 1999 é outorgada a Política Nacional de Educação Ambiental, a qual expõe no Art. $2^{\circ}$ "A educação ambiental é um componente essencial e permanente da educação nacional, devendo estar presente, de forma articulada, em todos os níveis e modalidades do processo educativo, em caráter formal e não formal.".

Ao longo dos anos 2000, o Ministério do Meio Ambiente vem implantando o Sistema Brasileiro de Informações sobre Educação Ambiental e Práticas Sustentáveis (SIBEA); a formação de coletivos educadores; Municípios Sustentáveis e seus educadores ambientais populares. No MEC, o "Vamos cuidar do Brasil com as escolas"; a formação das Com-vidas nas escolas; as Conferências de Meio Ambiente promovidas pelo Órgão Gestor do ProNEA, entre outras iniciativas institucionais.

Percebe-se assim que a Educação Ambiental já é uma realidade, para quais políticas públicas estão sendo traçadas necessitando, contudo, que esta institucionalização seja acompanhada por um devido aprofundamento crítico nas discussões por parte dos educadores em seu cotidiano e da sociedade em geral, para que essa se efetive como uma prática social que possibilite o enfrentamento da grave crise socioambiental. Portanto, Educação Ambiental: uma reflexão necessária.

\section{Por uma Educação Ambiental crítica}

Atualmente há grandes consensos na sociedade: o reconhecimento da gravidade dos problemas ambientais, que estes são decorrência de um modelo de desenvolvimento econômico de forte impacto ambiental e que a Educação Ambiental é uma importante ação para a superação destes problemas. No entanto, este reconhecimento não significa que estão sendo propostas soluções consensuais.

Recentemente circularam informações sobre resultados da pesquisa do INEP (2004), as quais dizem que mais de 94\% das escolas brasileiras reconhece que realizam Educação Ambiental (EA). Percebemos, no cotidiano escolar, cada vez mais, as crianças manifestando alguma inquietude e/ou aproximação com a questão ambiental; professores crescentemente procurando tratar dessa questão em suas aulas; a conquista da transversalidade e da abordagem interdisciplinar na legislação e 
políticas públicas sobre EA, como vimos anteriormente Ong's e empresas com um maior envolvimento com ações de EA. Acredito mesmo que, se fizéssemos uma pesquisa de opinião pública mundial, uma grande maioria da população afirmaria sinceramente que acha importante preservar a natureza. Certamente se fizermos um comparativo do quadro atual com o de 20, 30 anos atrás, poderemos ver o quanto a EA ganhou espaço na sociedade. No entanto, essa mesma sociedade degrada hoje mais o meio ambiente do que há 20, 30 anos.

O que pode explicar esse aparente paradoxo? Mais Educação Ambiental não está correspondendo a uma sociedade que degrade menos o meio natural. Parece que essa EA não está sendo eficaz para enfrentar a crise socioambiental que vivenciamos. Será que ainda é pouco tempo para percebermos resultados do processo educativo? Será que temos muito mais tempo para esperar por resultados educativos de longo prazo? Será por falta de uma produção acadêmica voltada para esta dimensão educativa? Será por falta de materiais didáticos para o desenvolvimento desta prática pedagógica no cotidiano escolar? Será que isso se dá pela falta de formação dos educadores para a EA? Por falta de fóruns de discussões sobre EA na sociedade, para que se dê uma formação continuada destes educadores? Será a falta de suporte técnico-metodológico para que as ações se tornem eficazes? Será que Educação não é tudo, apesar de anunciarem aos bordões o contrário?

Certamente todos estes fatores podem ser relacionados para buscarmos uma compreensão sobre este aparente paradoxo. Mas também precisamos ter claro que muita EA na sociedade não significa que estejamos enraizando uma concepção única dela. O que pretendo levantar como questão é que temos diferentes propostas de EA, segundo diferentes visões de mundo que as sustentam e que, acredito, com resultados diferenciados.

Algumas destas propostas de soluções para o enfrentamento da crise trabalham com a intenção de reformar o atual modelo de desenvolvimento via soluções tecnológicas e pela lógica do mercado, sem, portanto, alterar a racionalidade econômica que a informa. Outras trabalham com a perspectiva de mudanças de valores, hábitos e atitudes, individuais e coletivos, de uma nova ética e novas relações de produção e consumo substanciadas em diferentes paradigmas. Nesta

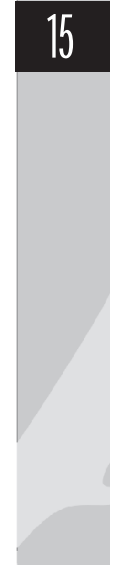


perspectiva, busca-se a transformação social e a construção de uma nova sociedade.

A Educação Ambiental é uma das dimensões do processo educacional, no entanto, podemos ter diferentes projetos educacionais que refletem e são reflexos de diferentes "visões sociais de mundo", em um espectro que alcança das visões mais conservadoras as mais críticas. $O$ caráter conservador compreende práticas que mantém o atual modelo de sociedade; enquanto crítico, o que aponta a dominação do Ser Humano e da Natureza, revelando as relações de poder na sociedade, em um processo de politização das ações humanas voltadas para as transformações da sociedade em direção ao equilíbrio socioambiental.

Portanto, se temos propostas conservadoras e críticas de Educação presentes na sociedade, certamente o mesmo ocorrerá com a Educação Ambiental, como procurei apontar em "Educação Ambiental: no consenso um embate?" (Guimarães, 2000).

Estas diferentes concepções de Educação travam um embate hegemônico. Uma atrelada "aos interesses populares de emancipação, de igualdade social e melhor qualidade de vida que se reflete em melhor qualidade ambiental; outra, que assume prioritariamente os interesses do capital, da lógica do mercado, defendida por grupos dominantes.” (Guimarães, 2000). Esta última, hegemônica na constituição da sociedade contemporânea.

Um projeto conservador de Educação baseado em uma visão liberal de mundo acredita que a transformação da sociedade é consequência da transformação de cada indivíduo, visto como seres em absoluta autonomia; a transformação depende da vontade individual. Desta forma, a Educação por si só é capaz de resolver todos os problemas da sociedade, basta ensinar o que é certo para cada um adquirir o comportamento correto, tornando-se assim uma Educação teórica, transmissora de informações e comportamentalista. Nesta concepção as relações sociais são secundarizadas no trabalho pedagógico, enfocando o indivíduo e a mudança de seu comportamento em uma visão atomizada. Sendo assim, poderíamos exemplificar: em um trabalho de Educação Ambiental realizado em uma madeireira, decorrente de condicionantes de licenciamento ambiental, se todos os seus empregados passassem por treinamento ambiental e mesmo que todos eles estivessem informados e sensibilizados para os riscos e consequências ambientais da destruição 
da natureza, isto bastaria para que esta empresa deixasse de desmatar de forma insustentável? Bastaria a vontade dos trabalhadores para transformar as práticas de produção daquela empresa? Isso, mesmo que somado para todos os trabalhadores do mundo, resolveria o problema da insustentabilidade do atual modelo econômico?

Em uma concepção crítica de Educação, acredita-se que a transformação da sociedade é causa e consequência (relação dialética) da transformação de cada indivíduo, há uma reciprocidade dos processos no qual propicia a transformação de ambos. Nesta visão, educando e educador são agentes sociais que atuam no processo de transformações sociais e nesse processo se transformam; portanto, o ensino é teoriaprática, é práxis. Ensino que se abre para a comunidade com seus problemas socioambientais, sendo a intervenção nesta realidade a promoção do ambiente educativo e o conteúdo do trabalho pedagógico. Aqui a compreensão e atuação sobre as relações de poder que permeiam e estruturam a sociedade são priorizados, significando uma Educação política, a qual nos faz perceber e ser os sujeitos que somos na história. No exemplo dos empregados da madeireira, seria educar ambientalmente esses trabalhadores como agentes sociais, incorporando estas questões em suas lutas sindicais e políticas em um exercício de cidadania cotidiana.

Em uma proposta crítica de Educação Ambiental trabalha-se com uma visão sistêmica de meio ambiente, compreendido em sua totalidade complexa como um conjunto no qual seus elementos/partes interdependentes interrelacionam entre si, entre as partes e o todo, o todo nas partes em uma interação sintetizada no equilíbrio dinâmico. $\mathrm{O}$ espaço natural veio historicamente sendo apropriado pelas sociedades humanas, transformando-o em um espaço socialmente produzido. A apropriação da natureza se deu sob o jugo das relações de dominação e exploração desta sociedade sobre o meio ambiente, em consonância com as relações de poder que perpassam as relações sociais. Tais relações se substanciam pela postura antropocêntrica que a humanidade exacerbou nos últimos séculos, colocando-se como o personagem principal da história planetária, justificando a exploração do meio ambiente a seu favor. Da mesma forma, a primazia do privado, do particular, do individual, da parte sobre o coletivo, sobre o todo, que se consolidou na história moderna e contemporânea, justifica a exploração do coletivo social, assim

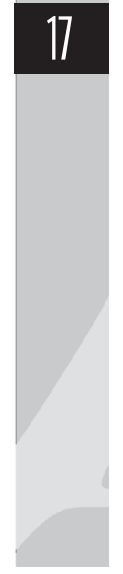


como o coletivo meio ambiente (conjunto em inter-relações) em favor de interesses particulares, o que prevalece no modo de produção capitalista. O conflito entre os interesses privados e coletivos estão na raiz das causas dos problemas socioambientais, conforme afirma Acserald (1993).

Esta forma desarmônica como as sociedades contemporâneas se relacionam com o meio ambiente, vem produzindo uma série de impactos socioambientais que atinge cada vez mais a capacidade que o ambiente tem de suportar estas intervenções. Este fato vem gerando problemas ambientais locais, assim como pela magnitude da capacidade produtiva $\mathrm{e}$ por extensão do consumo de recursos naturais e energéticos da sociedade industrial, bem como da não priorização da preservação das relações em equilíbrio do meio ambiente, agudiza-se os problemas socioambientais em escala global.

A gravidade dos problemas socioambientais que aponta até para a extinção da vida planetária e/ou humana denota uma crise ecológica sem precedentes na história do Planeta Terra, o que vem levar a um questionamento do modelo de desenvolvimento das sociedades urbanasindustriais. Como consequência deste questionamento surge o tão proclamado desenvolvimento sustentável, como um desenvolvimento econômico preocupado com a preservação ambiental para garantir a sobrevivência das gerações futuras. Vem sendo tratado genericamente como um "guarda chuva" que abriga desde os desamparados, vítimas das violências socioambientais do atual modelo desenvolvimentista, até os setores dominantes das sociedades que tem fortes interesses (econômicos) atrelados à manutenção do status quo. Mas terá este desenvolvimento sustentável propalado um novo modelo que supera o antropocentrismo? Será que propõe alterar as relações de poder que subjuga Seres Humanos e a Natureza? Será que prioriza o meio ambiente como um bem coletivo frente à atual primazia do privado? A problematização de tais propostas é uma postura cidadã que se faz pelo exercício crítico na produção social do espaço.

Sustentabilidade é um conceito que tem o seu sentido ainda em disputa na sociedade. Difundiu-se pelo movimento ambientalista como uma forma de relação entre uma nova sociedade e o meio ambiente que não levasse a degradação do segundo. Ou seja, uma proposta que pressupõe mudanças estruturais na organização social, alterando relações de poder 
atualmente instituídas. Certamente, a este sentido, esta racionalidade dominante o resignificou aproximando-o de sua lógica. Para esta racionalidade é uma forma de conciliação entre o desenvolvimento do modo de produção capitalista e medidas de preservação do meio ambiente. Eu acredito que no atual modo de produção, suas relações sociais, valores e práticas sociais, não construíram uma realidade socioambientalmetne sustentável. Portanto, creio que a construção da sustentabilidade passa por processos de transformações significativas desta realidade que está aí, e este é hoje um processo que precisa se realizar em escala planetária em sincronia com as transformações locais, que mesmo em suas invisibilidades se colocam a resistir.

Diferenças de sentidos, significados e proposições precisam ser percebidas e aprofundadas na análise dos educadores ambientais, já que propostas vêm sendo aceitas quase que consensualmente, sem grandes críticas. Deparamo-nos com um posicionamento que vem sendo apresentado de forma consensual na sociedade, o de que uma das principais funções do trabalho com o tema Meio Ambiente, entre outros, é o de contribuir para a formação de cidadãos conscientes ambientalmente.

Mas afinal, o que os educadores ambientais entendem por cidadania? Esta categoria vem sendo discutida por estes educadores? A noção de cidadania é consensual na sociedade?

Falar/escrever que a formação da cidadania é um dos principais objetivos da Educação, e da Ambiental em particular, sem uma melhor qualificação de sua concepção, como se fosse algo consensual entre todos os segmentos da sociedade brasileira, pode servir a uma homogeneização de uma importante categoria.

A homogeneização de uma categoria travestida em um falso consenso vela conflitos decorrentes de relações assimétricas de poder, que geram dominação/exclusão neste modelo de sociedade e retira o caráter crítico, problematizador e questionador desta categoria.

Sendo assim, para que cidadania seja uma categoria estratégica para a construção de um novo modelo de sociedade ambientalmente sustentável, dentro de uma perspectiva mais crítica para um projeto educacional, é preciso superar a compreensão dominante no senso comum, e propositiva pela visão de mundo (liberal) hegemônica, de que cidadão é o indivíduo passivo que respeita e pratica os direitos e deveres 
estabelecidos por esta sociedade, refletido nestes direitos e deveres as relações sociais desiguais. Ou ainda a de cidadão-consumidor, em que apenas a esses o sistema "escuta", excluindo a maior parte da população brasileira, que mal possui recursos para a sobrevivência do dia seguinte.

Assumir a dimensão política da cidadania e da Educação se faz fundamental para educadores ambientais e demais agentes sociais, já que parece que muitos na sociedade hoje, entre estes educadores, apesar de querer fazer algo para mudar esta realidade, apresentam práticas que não correspondem a esta expectativa.

Em meus últimos trabalhos, principalmente a partir do "A Formação de Educadores Ambientais" (2004), venho debruçando-me sobre a questão da formação destes educadores para um aprimoramento de suas práticas pedagógicas, que possam, diante de uma perspectiva crítica, contribuir na construção de uma sociedade socioambientalmente sustentável. Neste trabalho, aponto para a necessidade da superação de uma "armadilha paradigmática" a que estamos sujeitos, como forma de construir uma ação pedagógica de Educação Ambiental voltada para a transformação da realidade socioambiental.

Para Morin (1997), paradigmas são "estruturas de pensamento que de modo inconsciente comandam nosso discurso.", disso ressalta a força que os paradigmas tem nas nossas ações individuais e em nossas práticas sociais, a ponto de muitas vezes falarmos ou fazermos alguma coisa sem sabermos bem a razão, sem nem pensar sobre aquilo, "porque sempre foi assim por aqui"; assim, agimos no "automático". Isso nos faz perceber que os paradigmas tendem a nos levar a pensar e agir de acordo com algo pré-estabelecido, consolidado por uma visão de mundo que nos leva a confirmar (inconscientemente) uma racionalidade dominante. Essa é uma tendência conservadora que informam práticas individuais e coletivas que reproduzem os paradigmas e, portanto, a realidade que aí está.

Os paradigmas da sociedade moderna, chamados por Morin de paradigmas da disjunção por fragmentar e focar na parte, as separando, e quando as quer rejuntar formando uma totalidade, a realiza pela soma das partes. Isso simplifica e reduz a compreensão da realidade, limitando o entendimento de meio ambiente em sua complexidade que é muito mais do que apenas o resultado da soma das partes. Essa compreensão de mundo disjuntivo e dicotomizado não vem dando conta para estabelecer 
uma relação equilibrada entre essa sociedade e a natureza, o que se manifesta pela crise socioambiental.

Os educadores, apesar de bem intencionados, geralmente ao buscarem desenvolver as atividades reconhecidas de educação ambiental, apresentam uma prática informada pelos paradigmas da sociedade moderna. Não podemos deixar de relembrar que os indivíduos em geral, entre eles os educadores, seres sociais que somos, experienciamos em nosso cotidiano a dinâmica informada pelos paradigmas da sociedade moderna que tende a se auto perpetuar e que, seguindo essa tendência, é reprodutora de uma realidade estabelecida por uma racionalidade hegemônica.

É a essa dinâmica que estou chamando de armadilha paradigmática, quando por uma "limitação compreensiva e uma incapacidade discursiva" (Viégas, 2002), o educador, por estar atrelado a uma visão (paradigmática) fragmentária, simplista e reduzida da realidade, manifesta (inconscientemente) uma compreensão limitada da problemática ambiental e que se expressa por uma incapacidade discursiva, que cria amarras para o desenvolvimento de uma visão crítica e complexa do real, refletindo em uma prática pedagógica fragilizada de educação ambiental, produzindo o que Grün (1996) chamou de pedagogia redundante. Essa prática pedagógica presa à armadilha paradigmática não se apresenta apta a fazer diferente e tende a reproduzir as concepções tradicionais do processo educativo, baseadas nos paradigmas da sociedade moderna, sendo esse um poderoso mecanismo de alienação ideológica e de manutenção da hegemonia. Desta forma, essas práticas atreladas a essa armadilha, se mostram pouco eficazes para intervir significativamente no processo de transformação da realidade socioambiental, voltadas para a superação dos problemas e a construção de uma nova sociedade ambientalmente sustentável.

Como romper com essa armadilha, certamente, é algo fundamental de ser enfrentado na formação do educador ambiental, para que este possa, como sujeito de seu fazer pedagógico, incorporar práticas diferenciadas e criativas no movimento individual e coletivo de transformação e construção de uma nova realidade socioambiental. A ruptura dessa armadilha se dará na práxis pedagógica de reflexão crítica e ação participativa de educando e educadores, que una de forma indissociável teoria e prática, reflexão e ação, razão e emoção, indivíduo e coletivo, escola e comunidade, local

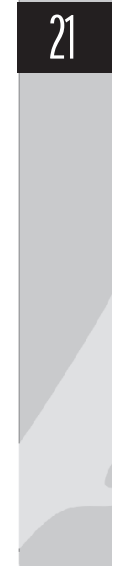


e global, em ambientes educativos resultantes de projetos pedagógicos que vivenciem o saber fazer criticamente consciente de intervenção na realidade, por práticas refletidas, problematizadoras e diferenciadoras, que se fazem politicamente influentes no exercício da cidadania.

Questões estas, entre tantas outras, que podem alimentar criticamente a constituição de movimentos contra hegemônicos na sociedade que se coloquem como antítese a uma tese dominante, potencializando o surgimento do novo em sínteses dialéticas constituintes do real em um processo de construção da sociedade socioambientalmente sustentável.

\section{REFERÊNCIAS}

ACSERLRAD, H. Ecologia: direito do cidadão. Rio de Janeiro: Gráfica JB, 1993.

BRASIL-INEP. Sinopse Estatística da Educação Básica. Brasília: MEC, 2004.

GRÜN, Mauro. Ética e Educação Ambiental: uma conexão necessária. Campinas: Papirus, 1996.

GUIMARÃES, Mauro. Os caminhos da Educação Ambiental: da forma a ação. Campinas: Papirus, 2006. 2004.

A Formação de Educadores Ambientais. Campinas: Papirus,

Educação Ambiental: no consenso um embate? Campinas: Papirus, 2000.

LOUREIRO, C. F. B.; LAYRARGUES, P.P.; CASTRO, R.S. (Org.). Pensamento Complexo, Dialética e Educação Ambiental. São Paulo: Cortez, 2006.

MORIN, Edgard. Complexidade e ética da solidariedade. In: CASTRO, G. de; CARVALHO, E. de A.; ALMEIDA, M. C. de (Coord.). Ensaios de Complexidade. Porto Alegre: Sulina, 1997.

SANTOS, Milton. A Natureza do Espaço: Técnica e Tempo, Razão e Emoção. $2^{\text {a }}$ Ed. São Paulo: HUCITEC, 1997.

VIÉGAS, Aline. A Educação Ambiental nos contextos escolares: para além da limitação compreensiva e da incapacidade discursiva. Dissertação de Mestrado. Niterói: UFF, 2002. 